\title{
An In-Depth Investigation of a Model Sport Program for Athletes with a Physical Disability
}

\author{
Jennifer Turnnidge, Matthew Vierimaa, Jean Côté \\ School of Kinesiology and Health Studies, Queen's University, Kingston, Canada \\ Email: 5jm14@queensu.ca,5mv5@queensu.ca, jc46@queensu.ca
}

Received September 26 ${ }^{\text {th }}$, 2012; revised October 24 $4^{\text {th }}$, 2012; accepted November $21^{\text {st }}$, 2012

\begin{abstract}
While previous research highlights the important benefits that sport participation can have for youth development, limited research has examined the sport experiences of athletes with disabilities (Martin, 2006). The purpose of this study was to describe the sport experiences of athletes with physical disabilities in a model swim program that has been widely recognized for the development of positive values in athletes. Semi-structured interviews were conducted with eight athletes with a physical disability. Participants were both male $(n=3)$ and female $(n=5)$, between 9 - 19 years of age, and averaged 5.9 years of swimming experience. Interviews were transcribed verbatim and were subjected to a content analysis procedure in which raw meaning units were grouped into salient themes (Côté, Salmela, Baria, \& Russell, 1993; Tesch, 1990). Athletes' responses regarding the outcomes derived from this program revealed four themes: 1) Redefined capabilities, 2) affirmed sense of self, 3) strengthened social connection, and 4) enhanced acceptance. Social and contextual processes facilitating the development of these outcomes are also discussed. Practical implications for programmers, coaches, and athletes are presented along with recommendations for future sport research.
\end{abstract}

Keywords: Positive Youth Development; Coaching; Peers

\section{Introduction}

Given the popularity and the significant amount of time youth spend in sport in comparison to other extracurricular activities (Guèvremont, Findlay, \& Kohen, 2008), sport is often advocated as an avenue through which positive development can be facilitated. Empirical research is beginning to verify this claim by suggesting associations between sport participation and several positive outcomes (e.g., Fraser-Thomas, Côté, \& Deakin, 2005; Larson, 2000). For example, participation in sport is linked with improved physical health, the acquisition of motor skills, and the development of important psychosocial skills (Côté \& Fraser-Thomas, 2007). While previous research provides valuable insight into the types of positive developmental outcomes that may be acquired through sport, the existing literature predominantly focuses on the sport experiences of able-bodied athletes. Studies examining the sport experiences of athletes with disabilities are relatively limited in comparison (Martin, 2006).

The need for research specifically examining sport participation among youth with disabilities is underscored by the fact that individuals with disabilities tend to engage in fewer physical and social activities compared to youth without disabilities (King et al., 2006). Studies exploring social interactions in disability sport are particularly relevant as previous research indicates that youth with disabilities may be at increased risk for peer rejection or neglect (Martin \& Choi, 2009). Finally, since it has been suggested that sport may provide an effective avenue to combat the discrimination and stigma commonly experienced by individuals with disabilities (Giacobbi, Stancil, Hardin, \& Bryant, 2008), research within this setting is warranted. Fortunately, there is growing support for the notion that sport can be a fertile developmental context for youth with disabilities (e.g., Kristén, Patriksson, \& Fridlund, 2002; Martin, 2006). Previous research suggests that sport can have a positive influence on youth's development of new physical and social skills (Groff \& Kleiber, 2001). Sport is also advocated as a context which can provide opportunities for feelings of mastery and accomplishment, which in turn can be linked to an enhanced sense of empowerment, self-confidence, and self-efficacy (e.g., Hutzler \& Sherill, 1999). Furthermore, sport may provide a salient context for the social development of athletes with disabilities. Research indicates that sport can offer opportunities for interactions and friendships with other individuals with disabilities that are not readily available in school or other community environments (Groff \& Kleiber, 2001). Through these opportunities, young athletes can experience shared responsibilities, common goals, and a sense of belonging (Goodwin, Krohn, \& Kuhnle, 2004; Shapiro \& Martin, 2010).

Given the various benefits that are linked with participation in sport, it is evident that sport can significantly contribute to the development of athletes with disabilities. Nonetheless, while the existing literature sheds some light on the types of outcomes that may be associated with sport participation, research is needed to evaluate the processes through which these outcomes can be acquired. Previous studies in various physical activity settings suggest that variables such as individual's self-perceptions (e.g., self-efficacy) and social and environmental factors (e.g., peers) may help to determine whether adapted physical activity will facilitate positive outcomes (e.g., Spencer-Cavaliere \& Watkinson, 2009).

For instance, Martin (2006) explored a wide range of psychosocial variables that may contribute to youth's motivation towards sport participation and their sport commitment. Results 
indicated that athletes' sport enjoyment and perceptions of physical ability were strongly related to youth's desire to continue participating in sport, thereby suggesting that youth's individual perceptions may play a key role in facilitating positive outcomes. Hutzler, Fliess, Chacham, and Van den Auweele (2002) echoed this sentiment as their investigation revealed that the self-efficacy and goal perspectives of students with disabilities influenced their perceptions of empowerment. Moreover, Hutzler and colleagues (2002) found that external factors, such as peers and important adults, also fostered empowerment within inclusive physical education.

Collectively, these studies suggest that both individual and contextual factors can affect youth's development within adapted physical activity settings. However, while this research illustrates some important pathways through which adapted physical activity may contribute to youth's development, the underlying mechanisms that influence the relationships between activity participation and positive outcomes are still not fully understood. As such, there is a need for theory-driven research assessing: 1) Youth's developmental experiences in adapted physical activity programs, 2) how development occurs, and 3) what effective practitioners do to support development. Lastly, although there is a growing body of literature on youth's adapted physical activity experiences, previous research has tended to focus on physical education settings (Spencer-Cavaliere \& Watkinson, 2010). Studies investigating youth's experiences within organized sport contexts may consequently help to supplement the existing literature.

One theoretical framework that may contribute to our understanding of the processes by which sport can influence athletes with disabilities is the positive youth development (PYD) approach. This approach suggests that researchers should examine the factors and experiences that may influence youth development from a positive or "asset-building" perspective that views youth as a resource to be developed, rather than a problem to be solved (Damon, 2004). PYD is thus a strength-based approach and its proponents envision all youth as having the potential for positive developmental change. This approach aims to educate and engage youth in productive activities and pro-social behaviors, instead of correcting perceived deficiencies (Damon, 2004). Consequently, this approach may be complementary to conceptualizations of disability sport as a context for empowerment and growth.

Research employing the PYD perspective indicates that sport may indeed be an ideal avenue for promoting positive developmental outcomes. For example, previous studies indicate that participation in sport programs may facilitate outcomes such as teamwork and initiative (Holt, Tamminen, Tink, \& Black, 2009; Larson, 2000). Recent theoretical research also proposes that sport programs have the potential to foster key aspects of positive development, such as competence, confidence, connection, and character (referred to as the 4Cs; Côté, Bruner, Erickson, Strachan, \& Fraser-Thomas, 2010). Nonetheless, while there is growing evidence that sport may provide an effective vehicle for facilitating positive development, this body of literature also highlights that there is nothing special about sport per se that automatically results in positive developmental outcomes. Simply engaging in sport is not sufficient to develop positively. Rather, it is posited that the outcomes of sport participation, positive or negative, depend on the complex interaction of several contextual and social factors.

Fortunately, there is a growing body of literature investigat- ing the social and contextual features of sport programs that may contribute to PYD. Frameworks put forth by FraserThomas, Côté, and Deakin (2005) and Petitpas, Cornelius, Van Raalte, and Jones (2005) propose that positive development is enhanced when: 1) Youth acquire developmental outcomes, 2) activities are conducted within appropriate contexts and 3) when youth are surrounded by positive external assets, such as supportive relationships with coaches and peers. As such, these frameworks reinforce the notion that positive development in sport is the product of on-going interactions between the person and the environment.

One important determinant of the quality of youth's sport experiences may be the sport context, which includes an individual's physical and social environment (Petitpas et al., 2005). In their review of previous literature, the National Research Council and Institute of Medicine (NRCIM, 2002) identified eight contextual setting features that can facilitate positive development in youth. These setting features include: 1) Physical and psychological safety; 2) appropriate structure; 3) supportive relationships; 4) an opportunity to belong; 5) positive social norms; 6) support of efficacy and mattering; 7) opportunities for skill building; and 8) integration of family, school, and community. Recent research in elite sport contexts suggests that programs that cultivate these setting features can positively influence youth sport experiences (Strachan, Côté, \& Deakin, 2011). However, these setting features have not yet been examined in a disability sport context.

Furthermore, although the right context is integral to facilitating youth development, it is often the social interactions and relationships that determine the quality of youth's sport experiences (Petitpas et al., 2005). Indeed, it is well documented that coaches play a crucial role in fostering positive development in youth (Horn, 2008). Moreover, previous research indicates that peers (Ullrich-French \& Smith, 2006) and parents (Côté, 1999) are both key elements of youth's sport experiences. Despite the importance of these social agents, limited research has examined how social relationships shape and support youth development within sport programs for athletes with disabilities (Shapiro \& Martin, 2010).

In order to advance the literature with respect to positive development in youth, there are several important avenues for future research. First, previous research suggests that studies are needed to not only examine the outcomes associated with sport participation, but to explore the types of processes and interpersonal interactions that may influence the development of these outcomes in model sport settings (Holt \& Sehn, 2008). Previous research also suggests that qualitative methodologies may be well suited to understanding the experiences of those involved in youth sport since they can provide in-depth accounts of athletes' perceptions of the processes that influence their development (Holt \& Jones, 2008). This is congruent with Spencer-Cavaliere and Watkinson's (2009) assertion that the viewpoints of youth with disabilities will help to enhance our understanding of their experiences in adapted physical activity contexts. Finally, Lerner (2002) argues that more research with 'real world' community programs is needed to identify the characteristics of sustainable and effective youth programs that can promote positive youth development. Consequently, studies exploring youth development in existing community sport programs that have been shown to lead to positive outcomes may be beneficial, particularly within the disability sport context. 


\section{Purpose of the Study}

Given the increased recognition of the role that organized sports play in facilitating positive youth development in general and for athletes with disabilities in particular, an investigation of these organized sport contexts is of critical importance. Previous studies underscore the need to identify and understand the processes that may contribute to youth's development in real world sport programs (Lerner, 2002; Petitpas et al., 2005). Furthermore, research suggests that examining sport experiences from the perspectives of the participants themselves may help to illuminate the role of sport programs in youth's development. Therefore, the purpose of this exploratory, qualitative study was to examine the sport experiences of young athletes with physiccal disabilities in a model swimming program. More specifically, this study hoped to uncover youth's perceptions of the outcomes derived from participating in this program as well as the processes that contributed to the acquisition of these outcomes.

\section{Method}

This study employed a qualitative descriptive research design. The aim of qualitative descriptive studies is to offer a comprehensive summary of the nature and shape of the participants' experiences (Sandelowski, 2000). Qualitative descriptive studies are designed to produce detailed and interpretive findings that are close to the data as given. In using this design, this study hoped to capture the experiences of youth sport participants within this program and to gain greater insight into the processes that facilitate these experiences from the perspectives of the youth themselves.

\section{Participants}

All procedures for this study were approved by the research ethics board at the researchers' university prior to initial contact with participants. The coach, the athletes, and the athletes' parents were required to provide written consent prior to participation. The program in this study was a competitive swim team for athletes with physical disabilities, located in eastern Ontario, Canada. This particular program was selected as it has both a record of elite performance and a reputation as a positive sport environment. This program has had two athletes qualify and compete at international competitions and has had several athletes compete at the provincial and national levels. This program has also been recognized for its high level of community involvement and its dedication to charitable endeavors by both local and national media. Moreover, the coach of the program has raised over one million dollars in support of youth with disabilities and has been appointed as a member of the Order of Canada in recognition of her accomplishments and service to the field of disability sport. Another distinctive aspect of this program is that the head coach intentionally designed the program for athletes with disabilities. This is in contrast to Cregan, Bloom, and Reid's (2007) finding that elite coaches of swimmers with a disability tended to coach able-bodied athletes until an athlete with a disability arrived at one of their practices.

Finally, this program was selected for its diverse range of athletes within the program. Indeed, this program includes athletes who represent a wide range of ages and competitive levels. Participants were purposefully sampled with maximum variation to gain an understanding of the wide variety of experiences of athletes within the program. Participants were eight athletes with a physical disability from this swim program. Participants were both male $(n=3)$ and female $(n=5)$, between 9 - 19 years of age, and averaged 5.9 years of swimming experience.

Participants represented a wide range of disabilities as determined by their sport classification categories (Dummer, 1999). Swimmers with a disability are classified based on several factors (e.g., muscle strength, co-ordination). Within this classification system, the lower the number of the class, the greater the functional impairment (e.g., class 1 represents a severe disability and class 10 represents a less severe disability). Participants in this study ranged from most severe to least severe as follows: classes $6(n=3), 8(n=2), 9(n=1)$, and $10(n=2)$. Participants also represented a wide range of competitive levels, from the recreational level to the international competitive level (see Table 1 for a detailed participant table).

\section{Procedure}

Semi-structured interviews were conducted with each of the participants in a private room at the sport complex. Interviews were conducted by the lead author, a female graduate student who had received training in qualitative methods. The second author, a male graduate student trained in qualitative methods, was also present during the interviews. His role involved taking notes during the interviews and to ensure that the findings which emerged from the interviews were not a result of personal bias or leading questions. Both researchers had attended several of the team's practices over a period of five months prior to the interviews, but had few direct interactions with the participants. By creating a sense of familiarity, the participants and researchers alike felt comfortable enough to enable an unconstrained exchange of dialogue.

Prior to the start of the interview, the participants were given introductory statements regarding the study rationale, the use of interview data, issues of confidentiality, the topics to be discussed, and procedures for recording and transcribing the interview. These preliminary procedures were implemented as part of the trust and rapport building process between the interview participant and the interviewer (Fontana \& Frey, 2000). These procedures were important to ensure that detailed, rich descriptions emerged later in the interview to the questions most relevant to the research questions of interest.

Following these procedures, a number of open ended questions were asked in order to stimulate thoughtful and detailed accounts of the athletes' experiences within this sport program.

Table 1.

Summary of the participants.

\begin{tabular}{ccccc}
\hline Participant & Age & Gender & Classification & $\begin{array}{c}\text { Competitive } \\
\text { Level }\end{array}$ \\
\hline P1 & 16 & Male & S8SB8SM8 & International \\
P2 & 15 & Male & S6SB6SM6 & National \\
P3 & 9 & Female & S10SB9SM10 & Regional \\
P4 & 15 & Male & S9SB9SM9 & Provincial \\
P5 & 16 & Female & S10SB9SM10 & Provincial \\
P6 & 11 & Female & S8SB7SM8 & Provincial \\
P7 & 19 & Female & S6SB6SM6 & International \\
P8 & 17 & Female & S6SB6SM6 & National \\
\hline
\end{tabular}


The main questions of the interview focused directly on participants' perceptions of the outcomes they achieved through participation in the program and their perceptions of the processes affecting their sport experiences. Sample questions included: "What have you learned since becoming a member of this program?" and "Please describe what aspects of the team have had the greatest impact on you?” Probing and follow-up questions were used to encourage the participants to elaborate on their ideas throughout the interview process (Patton, 2002). Sample probes included: "Tell me more" or "Could you please give me an example?” Specific questions were developed based on past developmental and sport psychology research and focused on aspects of the program structure and social influences (e.g., Fraser-Thomas et al., 2005; Petipas et al., 2005). Participants were also given an opportunity at the end of the interview to discuss any topics that may have remained unspoken to that point in time.

\section{Data Analysis}

Each interview was digitally recorded and transcribed verbatim, assigning each participant a code (P1 to P8). Content analysis was used in accordance with previously established guidelines (Côté, Salmela, Baria, \& Russel1, 1993; Tesch, 1990). Transcripts were read several times to allow for familiarization with each participant's responses and to obtain a sense of the data as a whole (Tesch, 1990). Data were then read word by word to look for meaningful units of information (i.e., segments that contain one specific idea or piece of information; Tesch, 1990). Each meaning unit was labeled with a tag that emerged from the text and that represented the information within the meaning unit. Tags were then compared and patterns of similarity and dissimilarity were identified. These patterns were then reviewed and clustered to identify salient themes within the data (Patton, 2002). The purpose of creating these themes was to provide a means of describing the athletes' experiences and to increase our understanding of the processes that shaped those experiences. Given that qualitative analysis often involves a mixture of inductive and deductive processes (Patton, 2002), it is important to recognize that every study is guided by certain concepts. In the present study, we were guided by the PYD approach, but made every effort to be receptive to unanticipated themes that were outside of this area of literature. In line with this contention, the research team selectively applied theoretical constructs to advance our interpretation of the data, thus avoiding "forcing" the data into predetermined categories. Hence, we used several PYD concepts to help organize the developmental outcomes and processes associated with the athletes' experiences in sport.

Throughout the analysis process, the research team met regularly to discuss the emerging themes. The research team consisted of the three authors and an external consultant. The third author and external consultant had extensive experience conducting qualitative research within youth sport settings. This process helped to ensure interpretive validity while minimizing individual researcher bias. Therefore, themes remained flexible during the investigation and were continuously examined, questioned, and refined until they accurately represented the qualitative material. Finally, once the final themes were constructed, the transcripts were re-read to ensure that all of the important aspects had been accurately captured.

Trustworthiness. The trustworthiness of the data was assured through a variety of methods. First, credibility was established through the provision of the participants' direct quotations, so that readers can evaluate and extend the conclusions drawn by the research team. Second, descriptions of multiple participants' experiences were provided to address the issue of transferability. Finally, dependability was enhanced through the use of a research team. Two members of this research team were involved in data analysis. Researchers' independent analyses were then followed by collaborative discussion with the entire research team, which led to minor refinements. Classification consistency was also verified through a reliability check that was conducted by an independent researcher familiar with qualitative research analysis. The independent researcher categorized a random sample (15\%) of the meaning units into the themes. The reliability check demonstrated high agreement (32 out of 33 units; 97\%).

\section{Results}

Overall, the results indicated that the athletes felt that their participation in this program provided them with a myriad of positive experiences. The athletes' responses regarding the outcomes derived from this program revealed four common themes: 1) Redefined capabilities, 2) affirmed sense of self, 3) strengthened social connection, and 4) enhanced acceptance. In addition, three themes emerged from the data relating to the athletes' perceptions of the processes that affected their sport experiences. These themes reflected social influences including: 1) Coach-athlete relationships, 2) peer interactions, and 3) the team environment.

\section{Outcome 1: Redefined Capabilities}

The athletes' experiences in this program provided them with an opportunity both to discover new skills and to re-evaluate the limits of their abilities. All of the athletes $(N=8)$ discussed how they had developed new physical skills, such as learning different strokes and refining their techniques. The significance of these accomplishments was underscored by the fact that some of the athletes had not known how to swim before entering the program and are now competing at the provincial, national, and even international levels. Athletes also commented on how gains in their physical competence had influenced other people's perceptions of their disability. As one athlete highlighted:

Before I was a little tight CP kid, I could barely even move. I couldn't really fit in playing with other people... now, as I'm getting older and I've swam more, my right side basically isn't noticeable. Most people at school don't even know I have a disability (P1, M, Age 16).

Moreover, the athletes expressed how developing new skills had enabled them to experience a sense of accomplishment and to develop pride in their abilities. For instance, athletes spoke of the pleasure of knowing that their newfound skills had challenged other people's attitudes towards people with disabilities. One athlete expanded:

Being able to do something that's different from other people makes me feel better cause it was hard when I was little cause I could hardly do anything. I just feel that swimming and stuff helps me cause I've had people make fun of me and now they don't really do that anymore because I can do something (P3, F, Age 9). 
Finally, the athletes suggested that this program provided a unique context that helped them to acquire skills that extended beyond the sport environment. Specifically, the athletes commented how their sport experiences had fostered the development of responsibility, time management, and work ethic. As one athlete indicated: “It's just wonderful because I have a responsibility to the team that's helping me get farther with my everyday life" (P1, M, Age 16).

\section{Outcome 2: Affirmed Sense of Self}

All of the athletes highlighted how their experiences in this program had enabled them to develop both a stronger selfconcept and an enhanced sense of confidence $(N=8)$. More specifically, athletes spoke of how their participation in swimming had afforded them the opportunity to feel more confident in their physical abilities and interpersonal skills. The athletes also described how their swimming experiences had encouraged them to set goals for themselves and to develop higher self-expectations. Indeed, many of the athletes revealed that they had never dreamed of athletic success, but had now set goals to compete at the provincial, national, and even international levels. One athlete recalled with enthusiasm how their goals had evolved since participating in this program:

I made the national team 3 years into my swimming career and to me, that was the beginning of my goals cause I saw 'holy smokes, I can go somewhere with this'... My next goal is the Paralympics. I'm so close and I've hit that point where I can say 'this is the foreseeable future'. So, that's really exciting (P7, F, Age 19).

In addition, athletes emphasized how the team environment had encouraged them to become independent individuals. The athletes spoke of having opportunities to demonstrate independence during their everyday practices and at their annual training camp. For example: "I've learned a lot of independence. Beforehand, I was very dependent on other people, but I've learned to stay away from that” (P8, F, Age 17).

\section{Outcome 3: Strengthened Social Connection}

One of the most dominant themes related to the social benefits that the athletes felt they had gained through their involvement in this program $(N=8)$. The athletes consistently reported making new friends since becoming a member of the team. Athletes also discussed how they had found opportunities to be around these new friends outside the swimming context, such as having dinner or going to the movies. Interestingly, the athletes commented on how the social environment of the swim program was unique from other contexts. As one athlete indicated:

Just having fun together, swimming together, competing together. It's just fun because sometimes at school there are people that are not a good sport and then you come to practice after school and you're here with people that are good sports (P3, F, Age 9).

In addition to developing close friendships, the athletes commented on how they had learned to work together as a team. The athletes highlighted how the range of age groups within the team had provided them with an opportunity to develop their leadership skills. They also stressed that they had learned about the importance of encouraging and helping their teammates both during practices and competitions. Furthermore, the ath- letes spoke of how they had enhanced their interpersonal skills and confidence in relating to peers.

On top of the improved peer relationships, the athletes discussed how their participation in the program had provided them with positive adult role models. In particular, athletes emphasized their positive relationships with the coach, who was often described in glowing terms such as the "great", "phenomenal" and the "best coach ever". Athletes expressed how they felt that she was more than a coach, but also a mentor and a close friend. As one athlete indicated: "My relationship with [the coach] is awesome, we can practically talk to her about anything” (P6, F, Age 11). Moreover, the athletes described the parents on the team as positive role models. They commented on their willingness to provide instrumental support, such as driving them to practice, officiating at competitions, and organizing team events. The athletes also described how the requirements of the team's practices and competitions had enabled the parents to become a great source of motivational and emotional support. One athlete expanded on the parent's role within the program:

They're [the parents] are always helping out and organizing events... They actually are a huge part of the team. As much as they play a part, they should be a part of the team (P5, F, Age 16).

\section{Outcome 4: Enhanced Acceptance}

The final outcome theme that emerged from the data related to how the athletes felt that they had learned to become more accepting of both their own and other's disabilities $(n=7)$. Athletes commented on how their sport experiences had enabled them to come to terms with their own disabilities and to look at themselves in a more positive light. As one athlete described the most important thing she had learned from this program: "That there's a lot of people around us with disabilities and it's ok if you have a disability, cause even if you have a disability, you can still do a lot” (P3, F, Age 9). The athletes also reflected on how they had a developed a sense of belonging through their experiences in the swim program. Specifically, the athletes emphasized that they'd realized that they were not alone in the world. For example,

I know more that there's other people out there like me, that have the same thing as me and I'm not on my own in this crazy mixed up world. All in all, my view on me having a disability is that I'm just like anyone else (P8, F, Age 17).

With respect to accepting others' disabilities, the athletes described how they had become more knowledgeable regarding several different types of disabilities and how they had learned to be more open minded towards others. As one athlete highlighted:

I learned that you can't judge a book by its cover. So if someone's in a wheelchair you can't judge them and be like: You can't do this because you're in a wheelchair. They're just as capable of doing stuff as everybody else on the team (P5, F, Age 16).

Given these results, it is evident that the athletes believed that their experiences within this particular program had provided them with several positive outcomes. In addition to these four outcome themes, it is important to examine the three themes relating to the athletes' perceptions of the processes that affected their sport experiences and produced these outcomes. These process themes included three important social influ- 
ences.

\section{Process 1: Coach-Athlete Relationships}

A dominant finding that emerged related to the important role that the head coach played in facilitating positive sport experiences $(N=8)$. All of the athletes' emphasized that the outcomes they had acquired from the program were highly contingent on their close, personal relationships with the coach. Indeed, the athletes discussed how their sense of connection was enhanced by the fact that the coach was a great source of motivation, encouragement, and support. In particular, the athletes highlighted how the coach had cultivated caring and supportive relationships by: Demonstrating a belief in the athletes' abilities, initiating and guiding the goal setting process, and enabling both personal and physical development.

Several of athletes placed a great deal of emphasis on their coach's unwavering belief in them as athletes, whether this was to learn a new skill or to set and achieve a goal. The athletes also discussed how the coach's high expectations had fostered a sense of determination in the team and how she had given them the freedom to follow their own dreams. Furthermore, the athletes highlighted the positive impact of the coach teaching the principles of goal setting and monitoring their progress in achieving their goals. As one athlete commented: "She's [the coach] encouraged me to make my goals, to swim faster, and to swim in the deep end. When I first started, that was scary" (P4, M, Age 15). By consistently communicating high expectations for her athletes and expressing confidence in the athletes' capabilities to meet and exceed these expectations, the athletes believed that the coach had enhanced both their perceptions of competence and self-confidence.

Finally, the athletes highlighted how the coach created opportunities for them to not only develop as athletes, but more importantly, as people. This included the coach allowing her athletes to participate in wide range of competitions across the country and to travel to Florida for an annual training camp. Athletes also discussed how the coach designed numerous charity events and that these events had taught them how sport can be used to benefit others. Moreover, the athletes suggested that the coach had helped them develop into better people. For example, one athlete reflected on how the coach encouraged his development as a leader: "[The coach] usually sends me off with one of the little kids, like if they're having a bad day, and I'll help them. She notices that I'm really good with the little kids” (P1, M, Age 16).

\section{Process 2: Peer Interactions}

All of the athletes emphasized how their peer interactions had positively shaped the quality of their sport experiences $(N=$ 8). In particular, the athletes suggested that these interactions had afforded them an opportunity to develop several skills. For instance, many of the older athletes discussed how they had learned to adapt drills and games to better suit the needs of the younger athletes. As such, their peer interactions promoted the acquisition of skills that extended beyond the sport environment. The athletes also described how their everyday interactions, such as joking around or cheering each other on during practice, helped enhance their sense of connection by developing genuine care and concern for each other. Indeed, the athletes often reflected on experiences where they had encouraged and supported their teammates during difficult situations. As one athlete commented: "Day in and day out, we always prove to other swim teams what we can do and how the swimmers on the team can help other swimmers" (P8, F, Age 17).

The athletes' peer interactions provided a context through which they could both find meaningful role models and be role models themselves. Many athletes discussed how their swimming experiences had allowed them to model pro-social behaviors to the younger athletes on the team. Specifically, the athletes stressed the importance of motivating each other during hard training sessions and being friendly to everyone on the team. Athletes also highlighted how their teammates were a source of inspiration, whether this involved dealing with adversity, displaying self-confidence, or pushing the limits of their physical capabilities. For example: "Just the friendships that I've made and people that I've met inspire you, their stories impact who you are and what you perceive as possible for yourself” (P7, F, Age 19). In sum, the athletes felt that their peer relationships within this program had strengthened their belief in their capabilities and had cultivated their sense of confidence and determination.

\section{Process 3: Team Environment}

Finally, all of the athletes indicated that the team environment had positively contributed to their sport experiences $(N=$ 8). One sentiment that consistently emerged from the data was that the athletes often referred to the team as a family and that they felt extremely loved and accepted within the team environment. In particular, the athletes discussed how everyone on the team, from the coach, to the parents, and to the athletes themselves, was very welcoming and strove to make everyone feel that they were an integral part of the team. For example, when asked what they liked most about the team, one athlete reflected: "Just the welcomeness of it, that's had the most impact. Just knowing that people are always there for you" (P4, M, Age 15). Throughout the interviews, the athletes expressed that the inclusiveness of the team environment played a key role in enhancing their acceptance of both themselves and others.

Moreover, the athletes suggested that their sense of social connection was strengthened by the creation of a sense of family and camaraderie among the athletes, coach, and parents. Several of the athletes highlighted the critical role that parents played on the team, from driving them to practices and competitions to organizing team events. Moreover, athletes stressed the importance of the emotional support and encouragement provided by the team's parents. As one athlete commented:

Parents are such a key role and they are so supportive. Every single parent we have on the team is just so very supportive of their child and of their goals and their dreams and they encourage the rest of us (P7, F, Age 19).

\section{Negative Experiences}

In general, the results indicate that the athletes' believed that their experiences within this sport program positively contrib.uted to their physical and personal development. It is important to note, however, that the athletes were also asked to reflect on their negative sport experiences. Interestingly, all of the athletes had difficulty responding to this question $(N=8)$. When pressed, some of the athletes mentioned feeling tired and occasional arguments with teammates. Nonetheless, the athletes 
often followed such comments with statements of praise for the program. Indeed, when asked what they disliked about the program, one athlete responded:

I don't honestly know, I've never really thought about it... honestly I can't. You get a group of people together and the only thing I can say is we're a normal group of people, you know you have your tiffs every now and again because that happens with different personalities, but there's nothing that I dislike about the [team] (P7, F, Age 19).

\section{Discussion}

The purpose of this study was to explore youth's sport experiences in a model swim program for athletes with a physical disability. More specifically, this study hoped to uncover youth's perceptions of the outcomes derived from participating in this program as well as the processes that contributed to the acquisition of these outcomes. The discussion that follows focuses on findings that highlight sport's significant role in facilitating positive development and the program features that may be characteristics of positive developmental settings. Recommendations for future sport research are also presented.

The results suggest that participation in this sport program promoted several positive outcomes. Throughout the interviews, the athletes drew attention to the uniqueness of their team environment in contributing to their development of self-confidence and self-acceptance. This finding is in line with Kristén and colleagues' (2002) research which similarly found that athletes with disabilities reported gaining confidence and feeling accepted through participation in sport. These findings thus suggest that sport may serve as an effective vehicle to enhance youth's sense of self-worth. This may be particularly important for youth with disabilities as the construction of positive selfidentity has been shown to help combat isolation and stigma (Goodwin et al., 2009).

Another prominent theme that emerged from the interviews related to youth's enhanced perceptions of their own and their teammates' physical capabilities. The athletes also reported that their participation in this program afforded them opportunities to explore their physical potential that were not available in other contexts. Higher perceptions of competence have been linked with several developmental outcomes, including intrinsic motivation, sport commitment, and self-esteem (Côté et al., 2010). Competence in sport may also facilitate athletes' social development since athletic ability is highly valued by youth and can thereby serve as an effective means of obtaining acceptance and popularity among one's peer group (Martin, 2006). This may be particularly beneficial given that youth with disabilities are often at increased risk for peer rejection or neglect (Martin \& Choi, 2009).

Furthermore, the athletes highlighted that their sport experiences had taught them several critical life skills, including responsibility, time management, leadership, and teamwork. In particular, athletes described how the team's focus on helping others and the coach's dedication to personal development helped to foster the acquisition of these skills. The athletes' reports suggest that contextual and social factors can shape the development of athletes, both in and out of sport. The link between sport participation and life skill development is well documented in able-bodied sport (e.g., Holt et al., 2009). Consequently, the findings of this study add to the existing literature by suggesting that the disability sport context may also positively contribute to the development of life skills.

The four outcome themes that emerged from the data shared striking similarities to the 4Cs from the positive youth development literature in able-bodied sport. The 4Cs (competence, confidence, connection, and character) have been proposed as important indicators of the presence of positive youth development in sport (Côté et al., 2010). Firstly, competence refers to the positive view of one's actions within a particular activity (Jelicic, Brock, Phelps, Lerner, \& Lerner, 2007), a construct that clearly resonates with the theme of redefined capabilities. Second, the construct of confidence is reflected in the theme of an affirmed sense of self. Moreover, marked commonalities exist between this dimension and themes in previous disability sport research, including becoming someone (Kristén et al., 2002) and a stronger self (Goodwin et al., 2004). Likewise, the development of connection was mirrored in the theme of strengthened social connection and was also noted across the themes in the previously mentioned studies. Finally, Jelicic et al. (2007) proposed that character involves the virtues of integrity, sympathy, and empathy. As such, this construct is mirrored in the outcome theme of enhanced acceptance, particularly with regards to increased acceptance of others. By examining the outcome themes of this study in conjunction with previous literature, it is evident that the 4Cs framework may be applicable to the disability sport context. Furthermore, these findings lend support to the notion that the 4Cs can be viewed as desirable outcomes of sport participation (Côté et al., 2010).

While it is important to examine the outcomes that athletes acquired through their sport experiences, a novel contribution of the present study was the examination of the processes which facilitated the acquisition of these outcomes. First, a distinguishing aspect of athletes' experiences within this sport program was the high quality of the athletes' relationships with their peers, parents, and coach. Indeed, the athletes consistently pinpointed how these relationships had enriched their sport experiences in each of the outcome themes. This finding lends support to the contention that social interactions can play a central role in facilitating positive experiences (Hutzler et al., 2002; Spencer-Cavaliere \& Watkinson, 2010).

One socializing agent that significantly contributed to the quality of the athletes' sport experiences in this program was the coach. The athletes described how they perceived the coach to be more than a swim coach, but also a mentor and a friend. The athletes often attributed their positive experiences within the program to their close relationships with the coach. One pathway through which the coach in this study influenced her athletes' development was through her unwavering belief in the athletes' abilities. By expressing confidence in her athletes' abilities to develop skills and achieve challenging goals, the coach may have bolstered the athletes' perceptions of competence. Consistent with this perspective, the athletes expressed how the coach's support had both enabled them to be more confident in their physical and interpersonal skills and enhanced their sport commitment. This corresponds with FraserThomas and Côté's (2009) finding that coaches' belief in their athletes can positively influence athletes' self-efficacy and continued motivation towards sport. This pathway may be of particular importance since athletes with disabilities often perceive that others have low expectations of their capabilities (Taub, Blinde, \& Greer, 1999).

The coach also encouraged her athletes to set their own goals and to express their independence. In doing so, the coach's 
behaviors align with certain elements of autonomy-supportive coaching. Autonomy-supportive coaching styles are those that provide athletes with choice, offer opportunities for independent work, and acknowledge their athletes' feelings (Mageau \& Vallerand, 2003). Previous research within both able-bodied (e.g., Reinboth, Duda, \& Ntoumanis, 2004) and elite disability sport (Banack, Sabiston, \& Bloom, 2011) demonstrates important links between autonomy-supportive coaching behaviors and positive athlete outcomes, such as self-determined motivition and physical and psychological well-being. The present study extends this literature by illustrating how autonomysupportive coaching strategies can also be employed with young athletes with physical disabilities. For instance, the athletes described how the coach created opportunities for them to participate in a range of competitions, to demonstrate leadership, and to engage in the goal-setting process. As a consequence, it may be beneficial for future research to further examine how autonomy-supportive coaching behaviors may foster positive developmental outcomes among athletes with disabilities.

Overall, the results highlight the important role the coach played in shaping the sport environment. This is congruent with previous research in able-bodied sport which suggests that coaches can serve as important role models for their athletes and can thus have a considerable impact on their athletes' wellbeing (Horn, 2008). These findings may be particularly important given that there is currently a paucity of research examining the coaches of athletes with disabilities (Banack et al., 2011).

In addition to positive coach-athlete relationships, the athletes placed a great deal of emphasis on the importance of peer interactions within this program. Indeed, the athletes described how their sport experiences had provided them with a significant opportunity to make friends and to broaden their social networks. These findings complement previous research which suggests that sport may provide a salient context for social development, both in able-bodied (e.g., Ullrich-French \& Smith, 2006) and disability sport (e.g., Goodwin et al., 2004). Athletes also reported that the relationships they had gained through this program had enabled them to develop social skills, such as teamwork, and had enhanced their confidence in relating to teammates. These results are congruent with Gifford-Smith and Brownell's (2003) assertion that friendships can promote the acquisition of interpersonal skills, enhance self-esteem, and produce feelings of well-being.

In line with Goodwin and colleagues' (2009) study with adult wheelchair rugby athletes, the results also revealed that the peer interactions athletes had within this sport environment fostered a sense of belonging that they did not necessarily experience in other contexts (e.g., school). The importance of this finding is underscored by the fact that peer interactions can serve as a source of emotional security and can act as a protective cushion against some of the stresses and challenges which youth experience (Gifford-Smith \& Brownell, 2003). Interpreting the results in light of these studies, it is evident that peer interactions are an integral component of the youth sport experience.

However, while these studies provide some initial support for the important association between peer interactions and positive youth development, research in this area remains relatively sparse (Martin \& Smith, 2002). Consequently, ample opportunities exist for researchers seeking to understand the influence of peer interactions within disability sport.

The team environment represented another key mechanism through which this sport program promoted positive athlete outcomes. This successful sport program was characterized by several contextual factors that complement the NRCIM's (2002) eight setting features. As noted previously, the athletes stressed the significant role that their relationships with the coach played in fostering positive experiences, a theme which is congruent with the third setting feature of supportive adult relationships. The athletes also expressed how their sport experiences were influenced by their supportive relationships with the parents of the program. Consistent with previous literature, the athletes emphasized their parents' role in providing tangible support, such as supplying financial resources and transporting athletes to practices and competitions (e.g., Côté, 1999). Furthermore, the athletes commented on the importance of the emotional support provided by their parents with regards to supporting and encouraging the athletes' goals. This finding coincides with the work of Martin and Mushett (1996), which found that parents often provide the strongest support for individuals with disabilities to participate in sport. In line with the fifth setting feature, several of the athletes highlighted how both the coaches and parents in this program facilitated positive social norms, such as helping others.

Another prominent theme that emerged from the data was that this program provided its athletes with a place where they felt loved, appreciated, and accepted. This creation of a sense of inclusion and family lends itself to establishment of opportunities to belong (the fourth setting feature). This setting feature resonates with previous research suggesting that a sense of belonging may have important implications for youth with disabilities (e.g., Shapiro \& Martin, 2010). However, further research is needed to substantiate this claim. For example, future studies may wish to examine how close connections among athletes, coaches, and parents may act as a means for gaining social capital, building interpersonal trust, and enhancing selfdetermined motivation.

Results also revealed several manifestations of the program's support for efficacy and mattering (the sixth setting feature). Athletes described developing leadership and responsibility and having opportunities for recognition and accomplishment. In creating opportunities for its athletes to make valued contributions to the team, this sport program may have bolstered the athletes' sense of acceptance and belonging. Congruent with the findings of Spencer-Cavaliere and Watkinson's (2010), these opportunities also appeared to be associated with athletes' perceptions of increased competence. These perceptions of competence may have been further enhanced since the athletes perceived the program as a salient context to acquire numerous physical, social, and personal skills (the seventh setting feature). Finally, several of the athletes highlighted how the team actively created opportunities to integrate family (parents and siblings) into athletes' sport experiences. Given the variety of ways in which this successful sport program embodied the NRCIM's (2002) eight setting features, these findings reinforce that these features may have important implications for athletes' sport experiences (Fraser-Thomas et al., 2005; Strachan et al., 2011). Furthermore, these results support the use and the application of these theoretical constructs to the disability sport context.

In sum, the athletes' experiences within this successful program indicate that disability sport contexts that are character- 
ized by an inclusive environment and meaningful interpersonal relationships can result in a wide range of positive developmental outcomes. In an effort to establish connections between the outcome and process themes that emerged from the participants' experience, the authors have proposed a conceptual framework (see Figure 1). This framework suggests that the three process themes of coach-athlete relationships, peer interactions, and the team environment will interact with each other to create contexts that can facilitate positive development. Drawing upon previous PYD research, it is believed that these social processes will cultivate programs that are consistent with the NRCIM's (2002) eight setting features. Subsequently, this framework proposes that these processes will positively contribute to athletes' development through the promotion of outcomes that share conceptual links to the PYD constructs of life skill development and the 4Cs. Future research is now required to investigate the links presented within this framework.

\section{Limitations and Future Directions}

Before examining the possible implications of this study, it is important to consider the study's limitations. First, it is important to recall that this study was conducted as a case-study of a single sport environment and thus the observed qualities may only be reflective of this unique swimming environment. Nonetheless, they do provide insight into both the outcomes that can be fostered in an exemplary sport program and some of the processes that may facilitate the acquisition of these outcomes. Second, it was beyond the scope of the present study to examine the relationship between the athletes' perceptions of this program and the interactions occurring within this program. Future observational studies may thus be useful in exploring the content and structure of coach-athlete, peer, and parent interactions.

Finally, it is important to acknowledge that the athletes in this study provided overwhelmingly positive reviews of their sport experiences. Thus, these athletes' experiences in sport may not be representative of youth's experiences in other sport programs for athletes with disabilities and consequently, the results should be interpreted with caution. There are a variety of factors that may have contributed to the athletes' positive reviews. Several of the athletes indicated that this sport program provided social and contextual supports that were not readily available to them in other settings. Therefore, the disparities that exist between this sport program and other environments may have enhanced athletes' perceptions of the benefits of their sport experiences. Moreover, this program was often the athletes' first opportunity to participate in a program designed for athletes with physical disabilities. As such, the unique and novel nature of this particular sport program may have played a role in the abundance of positive results. To address this limitation, future studies should be conducted with multiple programs to see how generalizable the present findings are to other com-

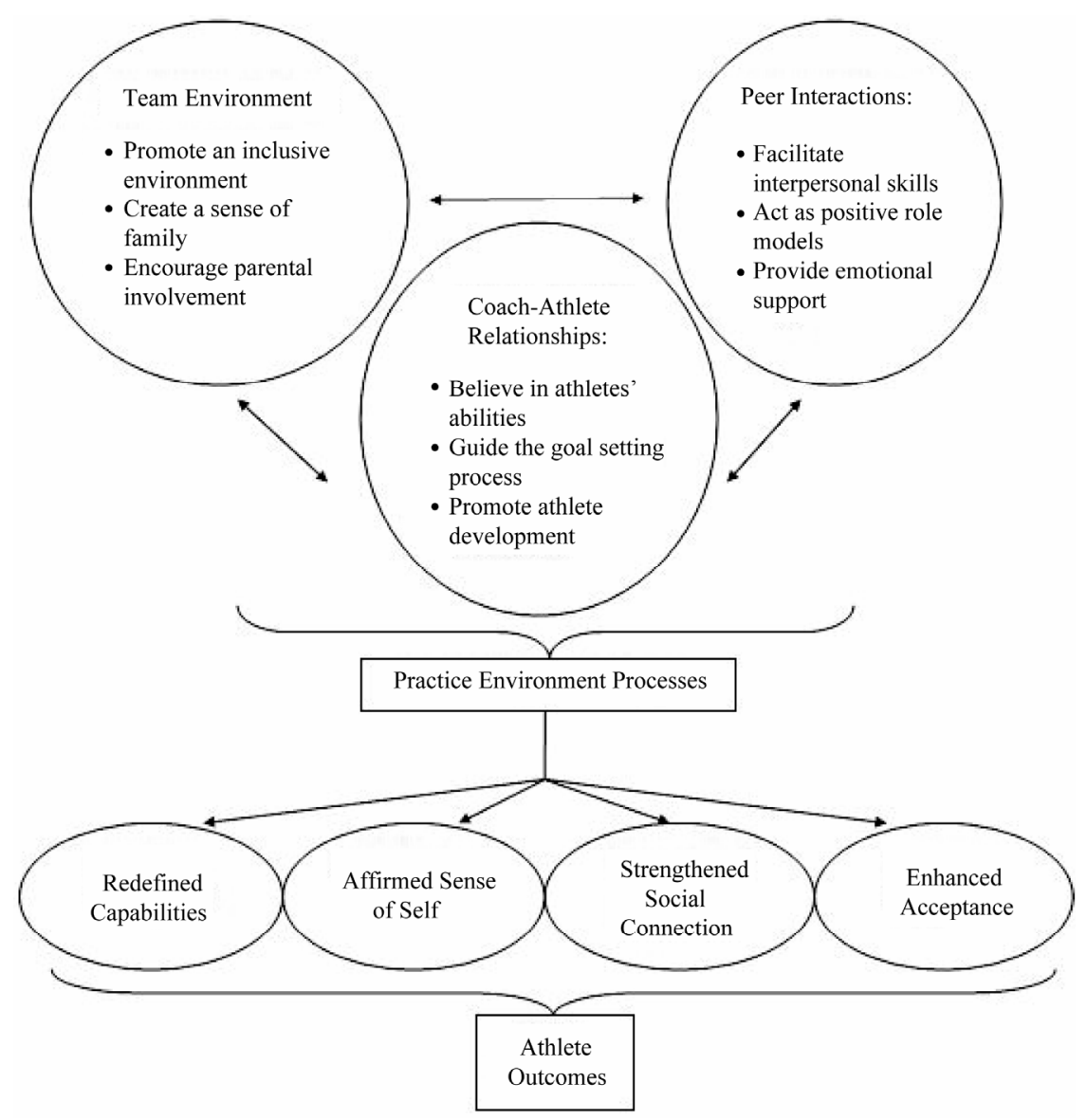

Figure 1.

Conceptual framework representing the athletes' experiences. 
petitive contexts. Research should also examine the sport experiences of athletes who have withdrawn from disability sport.

Overall, this study adds to the growing body of literature which suggests that sport may be an effective vehicle through which to study youth development. Findings of this study also indicate that the PYD approach holds significant potential for enhancing our understanding of the sport experiences of athletes with physical disabilities. Finally, the results illustrate how both social and contextual processes might shape the quality of youth's sport experiences. Although much research remains to be done, coaches and programmers that wish to increase the quality of their athletes' sport experiences can consider these processes when designing their programs.

\section{Acknowledgements}

The authors would like to thank Mark Bruner for his help, as well as the participants for enthusiastically donating their time. Preparation of this manuscript was supported by the Coaching Association of Canada and a Social Sciences and Humanities Research Council of Canada (SSHRC) standard research grant (\#410-2011-0472).

\section{REFERENCES}

Banack, H. R., Sabiston, C., \& Bloom, G. A. (2011). Coach autonomy support, basic need satisfaction, and intrinsic motivation of Paralympic athletes. Research Quarterly for Exercise and Sport, 84, 722-730. doi:10.5641/027013611X13275192111989

Côté, J. (1999). The influence of the family in the development of talent in sports. The Sport Psychologist, 13, 395-417.

Côté, J., Bruner, M. W., Erickson, K., Strachan, L., \& Fraser-Thomas, J. (2010). Athlete development and coaching. In J. Lyle, \& C. Cushion (Eds.), Sport coaching: Professionalism and practice (pp. 3-83). Oxford: Elsevier.

Côté, J., \& Fraser-Thomas, J. (2007). Youth involvement in sport. In P. R. E. Crocker (Ed.), Introduction to sport psychology: A Canadian perspective (pp. 270-298). Toronto: Pearson.

Côté, J., Salmela, J. H., Baria, A., \& Russell, S. J. (1993). Organizing and interpreting unstructured qualitative data. The Sport Psychologist, 2, 127-137.

Cregan, K., Bloom, G. A., \& Reid, G. (2007). Career evolution and knowledge of elite coaches of swimmers with a physical disability. Research Quarterly for Exercise and Sport, 78, 339-350. doi:10.5641/193250307X13082505158147

Damon, W. (2004). What is positive youth development? Annals of the American Academy of Political and Social Science, 591, 13-24. doi:10.1177/0002716203260092

Fontana, A., \& Frey, J. H. (2000). The interview: From structured questions to negotiated text. In N. K. Denzin, \& Y. S. Lincoln (Eds.), Handbook of qualitative research (2nd ed., pp. 645-672). Thousand Oaks, CA: Sage.

Fraser-Thomas, J., \& Côté, J. (2009). Understanding adolescents’ positive and negative developmental experiences in sport. The Sport Psychologist, 23, 3-23.

Fraser-Thomas, J. L., Côté, J., \& Deakin, J. (2005). Youth sport programs: An avenue to foster positive youth development. Physical Education and Sport Pedagogy, 10, 19-40.

Giacobbi Jr., P. R., Stancil, M., Hardin, B., \& Bryant, L. (2008). Physical activity and quality of life experienced by highly active individuals with physical disabilities. Adapted Physical Activity Quarterly, 25, 189-207.

Gifford-Smith, M. E., \& Brownell, C. A. (2003). Childhood peer relationships: Social acceptance, friendships, and peer networks. Journal of School Psychology, 41, 235-284.

doi:10.1016/S0022-4405(03)00048-7

Goodwin, D. L., Krohn, J., \& Kuhnle, A. (2004). Beyond the wheel- chair: The experience of dance. Adapted Physical Activity Quarterly, 21, 229-247.

Goodwin, D., Johnston, K., Gustafson, P., Elliott, M., Thurmeier, R., \& Kuttai, H. (2009). It's okay to be a quad: Wheelchair rugby players' sense of community. Adapted Physical Activity Quarterly, 26, 102 117.

Groff, D. G., \& Kleiber, D. A. (2001). Exploring the identity formation of youth involved in an adapted sports program. Therapeutic Recreation Journal, 35, 318-332.

Guèvremont, A., Findlay, L., \& Kohen, D. (2008). Organized extracurricular activities of Canadian children and youth. Health Reports, 19, 65-69.

Holt, N. L., \& Jones, M. I. (2008). Future directions for positive youth development and sport research. In N. L. Holt (Ed.), Positive youth development through sport (pp. 122-132). London: Routledge.

Holt, N. L., \& Sehn, Z. L. (2008). Processes associated with positive youth development and participation in competitive youth sport. In N. L. Holt (Ed.), Positive youth development through sport (pp. 24-33). London: Routledge.

Holt, N. L., Tamminen, K. A., Tink, L. N., \& Black, D. E. (2009). An interpretive analysis of life skills associated with sport participation. Qualitative Research in Sport and Exercise, 1, 160-175. doi:10.1080/19398440902909017

Horn, T. (2008). Coaching effectiveness in the sport domain. In T. S. Horn (Ed.), Advances in sport psychology (3rd ed., pp. 239-268) Champaign, IL: Human Kinetics.

Hutzler, Y., Fliess, O., Chacham, A., \& Van den Auweele, Y. (2002). Perspectives of children with physical disabilities on inclusion and empowerment: Supporting and limiting factors. Adapted Physical Activity Quarterly, 19, 300-317.

Hutzler, Y., \& Sherrill, C. (1999). Disability, physical activity, psychological well-being and empowerment: A life span perspective. In R. Lidor, \& M. Bar-Eli (Eds.), Sport psychology: Linking theory and practice (pp. 281-300). Morgantown, WV: Fitness Information Technology.

Jelicic, H., Bobek, D., Phelps, E., Lerner, R., \& Lerner, J. (2007). Using positive youth development to predict contribution and risk behaviors in early adolescence: Findings from the first two waves of the 4-H Study of Positive Youth Development. International Journal of Behavioral Development, 31, 263-273. doi: $10.1177 / 0165025407076439$

King, G., Law, M., Hanna, S., King, S., Hurley, P., Rosenbaum, P., Kertoy, M., \& Petrenchik, T. (2006). Predictors of the leisure and recreation participation of children with physical disabilities: A structural equation modeling analysis. Children's Health Care, 35, 209-234. doi:10.1207/s15326888chc3503 2

Kristén, L., Patriksson, G., \& Fridlund, B. (2002). Conceptions of children and adolescents with physical disabilities about their participation in a sports programme. European Physical Education Review, 8, 139-156.

Larson, R. (2000). Toward a psychology of positive youth development. American Psychologist, 55, 170-183. doi:10.1037//0003-066X.55.1.170

Lerner, R. M. (2002). Concepts and theories of human development (3rd ed.). Mahwah, NJ: Lawrence Erlbaum Associates, Inc.

Mageau, G., \& Vallerand, R. (2003). The coach-athlete relationship: A motivational model. Journal of Sport Sciences, 21, 883-904. doi:10.1080/0264041031000140374

Martin, J. J. (2006). Psychosocial aspects of youth disability sport. Adapted Physical Activity Quarterly, 23, 65-77.

Martin, J. J., \& Choi, Y. S. (2009). Parents' physical activity-related perceptions of their children with disabilities. Disability \& Health Journal, 2, 9-14. doi:10.1016/j.dhjo.2008.09.001

Martin, J. J., \& Mushett, A. C. (1996). Social support mechanisms among athletes with disabilities. Adapted Physical Activity Quarterly, 13, 74-83.

Martin, J. J., \& Smith, K. (2002). Friendship quality in youth disability sport: Perceptions of a best friend. Adapted Physical Activity Quarterly, 19, 472-482.

National Research Council and Institute of Medicine (2002). Commu- 
nity programs to promote youth development. Washington, DC: National Academy Press.

Patton, M. Q. (2002). Qualitative research and evaluation methods (3rd ed.). Thousand Oaks, CA: Sage Publications.

Petitpas, A. J., Cornelius, A. E., Van Raalte, J. L., \& Jones, T. (2005). A framework for planning youth sport programs that foster psychosocial development. The Sport Psychologist, 19, 63-80.

Reinboth, M., Duda, J. L., \& Ntoumanis, N. (2004). Dimensions of coaching behavior, need satisfaction, and the psychological and physical welfare of young athletes. Motivation and Emotion, 28, 297313. doi:10.1023/B:MOEM.0000040156.81924.b8

Sandelowski, M. (2000). Whatever happened to qualitative description? Research in Nursing and Health, 23, 334-340.

doi:10.1002/1098-240X(200008)23:4<334::AID-NUR9>3.0.CO;2-G

Shapiro, D. R., \& Martin, J. J. (2010). Athletic identity, affect, and peer relations in youth athletes with physical disabilities. Disability \& Health Journal, 3, 79-85. doi:10.1016/j.dhjo.2009.08.004
Spencer-Cavaliere, N., \& Watkinson, E. J. (2010). Inclusion understood from the perspectives of children with a disability. Adapted Physical Activity Quarterly, 27, 275-293.

Strachan, L., Côté, J., \& Deakin, J. (2011). A new view: Exploring positive youth development in elite sport contexts. Qualitative Research in Sport, Exercise, and Health, 3, 9-32. doi:10.1080/19398441.2010.541483

Taub, D. E., Blinde, E. M., \& Greer, K. M. (1999). Stigma management through participation in sport and physical activity: Experiences of male college students with physical disabilities. Human Relations, 52, 1469-1483. doi:10.1177/001872679905201106

Tesch, R. (1990). Qualitative research: Analysis types and software tools. Hampshire: The Falmer Press.

Ullrich-French, S., \& Smith, A. L. (2006). Perceptions of relationships with parents and peers in youth sport: Independent and combined prediction of motivational outcomes. Psychology of Sport \& Exercise, 7, 193-214. doi:10.1016/j.psychsport.2005.08.006 